\title{
Sciendo
}

DOI: 10.1515/aon-2019-0013

\section{ANALYTICAL - DIFFRACTION MODEL OF V-BAND PROPAGATION FOR THE RADIOCOMMUNICATION EVENTS MANAGEMENT SYSTEM (REMS)}

\author{
Marcin Mąka \\ Maritime University of Szczecin \\ Wały Chrobrego 1-2, 70-500 Szczecin, Poland \\ e-mail: m.maka@am.szczecin.pl \\ Piotr Majzner \\ Maritime University of Szczecin \\ Wały Chrobrego 1-2, 70-500 Szczecin, Poland \\ e-mail: p.majzner@am.szczecin.pl
}

\begin{abstract}
The paper presents an analytical-diffraction propagation model for the needs of the Radiocommunication Events Management System, for coast and ship radio stations in sea area A1. The V-wave propagation in sea area 1 has been analyzed as part of an analysis of ranges of particular radio stations and their ability to establish radio contact. The theoretical basis and assumptions on which the model structure design process is based have been presented. Methods of modelling and presentation of dislocation of particular radio stations and their ranges have been discussed.
\end{abstract}

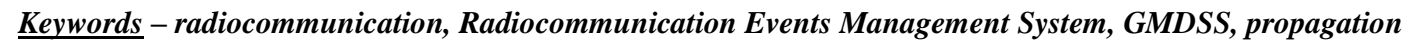

\section{INTRODUCTION}

The waves in the $\mathrm{V}$ band propagate straight as a spatial wave. They are reflected from the objects with a high density, dispersed and attenuated in the atmosphere and other centers. It is caused mainly by the presence of water in its various forms (rainfall, fog, etc.). The theoretical range of ultrashort waves is limited to the optical horizon. In practice, it is greater due to tropospheric refraction phenomena and diffraction.

The previous analytical methods developed in the second half of the last century, reflected in the ITU resolutions and publications, focused on determining the value of the electromagnetic field intensity as a function of the distance between the transmitting and receiving antennas. The necessity of using complex formulas and interpolation of the characteristics of many parameters caused difficulties in the quick and practical application of these methods by users of radiocommunication devices. Radio operators, who have to decide how to use the means of communication, are interested not in the field strength, but in the possibility of carrying out correspondence over a certain distance. For this reason, in the literature and textbooks of radio operators, the developed empirical relationships determining the range of communication are widely used $D$ [Czajkowski, 2002]:

$$
D=2,5\left(\sqrt{h_{1}}+\sqrt{h_{2}}\right)
$$


or in kilometers (2):

$$
D=4,2\left(\sqrt{h_{1}}+\sqrt{h_{2}}\right)
$$

where:

- $h_{l}-$ height of the transmitting antenna,

- $h_{2}$ - height of the receiving antenna.

However, the above formulae do not take into account the type of modulation and the type of signal (radiotelephony or digital transmission - DSC).

In the case of communication with the shore station, whose antennas are even several tens of meters above the surface, there may be a situation where only one way communication is possible. The radio station on the ship receives the signal from the shore station, while the signal transmitted from the ship is not picked up. In addition, this method does not take into account many factors affecting the range of communication among others changes in the conductivity of the ground along the path of the electromagnetic wave or the difference in the transmitters output power, which occurs in the case of communication between the ship and the shore station.

In addition, the lack of possibility to indicate differences in radiotelephony and DSC ranges using formulas 1 causes problems in modeling decision-making processes in the developed Radiocommunication Events Management System (REMS). Therefore, according to the authors, it was necessary to analyze and adapt the methods used so far to the requirements of the REMS system being developed, especially in the situation of changes in the provisions of the Radio Regulations and the introduction of new elements in the GMDSS.

\section{FIELD STRENGTH AND RANGE CALCULATIONS.}

The basis for the analysis is to determine the electric field strength in the free space $e_{0}$ according to the equation (3) [ITU-R P.525-3, 2016]:

$$
e_{0}=173 \frac{\sqrt{p k W}}{d_{k m}}
$$

where:

- $\quad e_{0}$ - r.m.s field strength $[\mathrm{mV} / \mathrm{m}]$

- $\quad p_{k W}$ - equivalent isotropically radiated power (e.i.r.p.) of the transmitter in the direction of the point in question $[\mathrm{kW}]$

- $d$ - distance from the transmitter to the point in question $[\mathrm{km}]$.

The transmission loss of the free space in relation to the isotropic antenna is determined from the formula [ITU-R P.341-6, 2016]:

$$
L_{b f}=32.4+20 \log f+20 \log d
$$

where:

- $\quad f$ - frequency $[\mathrm{MHz}]$,

- $d$-distance between antennas $[\mathrm{km}]$.

Based on the energy balance equation for the radio link [Instytut Lączności, 2005], [Katulski, 2002], [Saunders et al., 1999]: 


$$
\left(P_{t}+G_{t}-L_{t}\right)-L-\left(P_{r}+G_{r}-L_{r}\right)=0
$$

where:

- $P_{t}$ - transmitter output power,

- $P_{r}$ - the power of the received signal,

- $\quad L_{t}$ and $L_{r}$ - losses in circuits of transmitting and receiving antennas, respectively [dB],

- $G_{t}$ and $G_{r}$ - directivity gains of the transmitting and receiving antennas.

In sea conditions, in ship-to-ship communication, it is not necessary to take into account in the modeling process the impact of terrain and buildings. However, the effect of radio wave reflection on the sea surface (multi-directional propagation) is taken into account. The result of multi-directional propagation are signal losses resulting from direct wave interference and reflection from the surface of the sea. The least favorable situation occurs when there is no wave, when a small number of reflected waves causes a high probability of significant signal losses. On the other hand, in the case of a disturbed sea, when the number of reflections is high, and the phases of individual components are accidental in connectivity, the direct wave dominates. The likelihood of large signal losses is low. [Pawłowski, 2001], [Instytut Łączności, 2006].

Since the most important task of the developed propagation model is to determine the maximum communication range, one of the basic phenomena that should be taken into account is the diffraction of the wave over obstacles and the spherical surface of the earth [ITU-R P.526-13, 2013]. One should consider here the radius of the first Fresnel zone (Fresnel ellipsoid) Rn determined from the formula:

$$
R_{n}=550\left[\frac{n d_{1} d_{2}}{\left(d_{1}+d_{2}\right) f}\right]^{0.5}
$$

where:

- $f$ - frequency $[\mathrm{MHz}]$,

- $d_{1}, d_{2}$ - the distances [km] between transmitter and receiver at the point where the ellipsoid radius [m] is calculated,

- $\quad n$ - Fresnel ellipsoid number, in this case $n=1$.

The obstacle taken into account in the diffraction analysis may be considered as a single if the distance from the next obstacle is less than 0,6 radius of the first Fresnel zone $\left(R<0.6 R_{n}\right)$. The surface of the Earth can be considered as smooth if the radius of the curvature of the terrain unevenness is less than or equal to 0.1 the maximum value of the first radius of the Fresnel zone in the propagation path $\left(R<0,1 R_{n}\right)$ [ITU-R P.526-13, 2013], [ITU-R P.1546-5, 2013].

The measure of field intensity losses due to diffraction is the ratio:

$$
20 \log \frac{e}{e_{0}}=F(X)+G\left(Y_{1}\right)+G\left(Y_{2}\right)
$$

where:

- $e$ - loss of field strength due to diffraction,

- $F(X)$ and $G(Y)$ are respectively functions depending on the distance between the antennas and the heights $h_{1}$ and $h_{2}$ on which the transmit and receiving antennas are mounted towards the sea surface: 


$$
\begin{gathered}
F(X)=11+10 \log (X)-17.6 X \text { for } X \geq 1.6 \\
F(X)=-20 \log (X)-5.6488 X^{1.425} \text { for } X<1.6 \\
G(Y) \cong 17.6(B-1.1)^{0.5}-5 \log (B-1.1)-8 \text { for } B>2 \\
G(Y) \cong 20 \log \left(B+0.1 B^{3}\right) \text { for } B \leq 2
\end{gathered}
$$

where:

- $\quad X$ - the normalized length of the path between the antennas at normalized heights $Y_{1}$ and $Y_{2}$ :

$$
\begin{gathered}
X=\beta\left(\frac{\pi}{\lambda a_{e}^{2}}\right)^{1 / 3} d \\
Y_{i}=2 \beta\left(\frac{\pi^{2}}{\lambda^{2} a_{e}}\right)^{1 / 3} h_{i}
\end{gathered}
$$

where:

- $\alpha$-wavelength,

- $h_{i}$ - the heights at which the transmitting and receiving antennas are mounted respectively,

- $\quad \beta$ - parameter which is a function of ground conductivity in the propagation path and antenna polarization (table 1),

- $a_{e}$ - equivalent Earth's radius [km] [ITU-R P.310-9, 1994], [ITU-R P.1812-4, 2015]:

$$
a_{e}=a k
$$

where:

- $a$-real earth radius $(a=6371[\mathrm{~km}])$,

- $\quad k$ - effective earth radius factor.

As a result of such a geometrical transformation, linear radius trajectories are obtained, regardless of the elevation angle. It can then be assumed that the propagation path is horizontal. The gradient of the atmosphere refraction is then constant. For a height below $1000 \mathrm{~m}$, the exponential model for the medium refractive index profile can be approximated linearly. The value of the coefficient $k$ is then $k=4 / 3$ [ITU-R P.453-13 2017], [ITU-R P.834-9, 2017], [ITU-R P.1812-4, 2015].

The parameter $B$ from equation 9 is determined from the formula:

$$
B=\beta Y_{i}
$$

where $\beta$ is determined according to the table 1 or calculated from the formula:

$$
\beta=\frac{1+1.6 K^{2}+0.67 K^{4}}{1+4.5 K^{2}+1.53 K^{4}}
$$

where:

- $\quad K$ - is a parameter dependent on the effective earth radius factor, frequency and the conductivity of sea (equation 14).

Table 1. The dependence of the coefficient $\beta$ on the antenna's polarization and frequency

\begin{tabular}{|c|c|c|} 
Polarization & Terrain \& Frequency & $\beta$ \\
\hline \multirow{2}{*}{ horizontal } & $>20[\mathrm{MHz}]$, land & 1 \\
\cline { 2 - 2 } \multirow{2}{*}{ vertical } & $>300[\mathrm{MHz}]$, sea & \multirow{2}{*}{ Function of $K$} \\
\cline { 2 - 2 } & $<20[\mathrm{MHz}]$, land \\
\hline
\end{tabular}


Factor $K$ from equation 13 was calculated from the formula:

$$
K^{2} \approx \frac{\sigma}{k^{2 / 3} f^{5 / 3}}
$$

where:

- $\sigma$ - conductivity of sea [S/m] [ITU-R P.527-4, 2017] ,[ITU-R P.368-9, 2007], [ITU-R P.1812-4, 2015].

Conductivity is a parameter depending on the type and humidity of the ground on the propagation path and indirectly on the ambient temperature. With communication in the VHF band occurring through the surface wave over the inhomogeneous terrain, there are rapid changes in the intensity of the field near the interface of areas of different conductivity.

The receiving antenna, located in an area with higher conductivity than the conductivity of the transmitting antenna area, obtains a higher intensity of the field, which would occur if the area along the whole route had the same conductivity. In the opposite case, in the area of lower conductivity, the field intensity decreases. This phenomenon occurs particularly strongly at the transition from land to sea.

To calculate the field strength for propagation path through land and sea uses a formula [ITU-R P.1546-5, 2013]:

$$
E=(1-A) E_{\text {land }} d+A E_{\text {sea }} d
$$

where:

- $E_{\text {land }}$ - field strength value assuming that the whole propagation path length $d_{\text {total }}$ extends over land,

- $E_{\text {sea }}$ - field strength value assuming that the whole propagation path length $d_{\text {total }}$ extends over sea,

- $A$ - interpolation factor.

\section{MODELING - CALCULATING THE RANGE OF RADIO STATIONS.}

According to resolution ITU A.609(15) [ITU-A.609, 2015], assumptions were made for calculations that for audio communication the sensitivity of the receiver should be equal to or better than $2 \mu \mathrm{V}$ e.m.f. for a signal-to-noise ratio of $20 \mathrm{~dB}$. For digital selective calling, with a modulated DSC input signal of $1 \mu \mathrm{V}$ e.m.f. the receiver should be able to decode the received message with a maximum permissible error rate of $10^{-2}$

The radiotelephone coverage ranges determined on the basis of the developed model, when the antennas are mounted at a height above twenty meters, are very close to the ranges determined from the empirical formula (2) (table 1 and table 2). The ranges assigned for DSC are from 9 to 30 percent greater than the radiotelephone (table 3$)$.

Table 2. Calculated ranges (in kilometers) of radiotelephony communication as a function of the height of the antennas: transmitting and receiving, above the sea surface using formula (2)

\begin{tabular}{|c|c|c|c|c|c|c|c|c|c|c|}
\multicolumn{2}{|c|}{} & \multicolumn{10}{|c|}{$\boldsymbol{h}_{\mathbf{2}}[\mathbf{m}]$} \\
\cline { 3 - 11 } \multicolumn{2}{|c|}{} & $\mathbf{1 0 , 0}$ & $\mathbf{2 0 , 0}$ & $\mathbf{3 0 , 0}$ & $\mathbf{4 0 , 0}$ & $\mathbf{5 0 , 0}$ & $\mathbf{6 0 , 0}$ & $\mathbf{7 0 , 0}$ & $\mathbf{8 0 , 0}$ & $\mathbf{9 0 , 0}$ \\
$\mathbf{1 0}$ & 20,6 & 27,2 & 31,7 & 35,3 & 38,2 & 40,8 & 43,2 & 45,3 & 47,3 \\
\hline $\mathbf{3 0}$ & 27,2 & 35,1 & 40,3 & 44,3 & 47,6 & 50,5 & 53,0 & 55,3 & 57,5 \\
\hline $\mathbf{\Xi}$ & $\mathbf{5 0}$ & 38,2 & 47,6 & 53,6 & 58,0 & 61,7 & 64,8 & 67,6 & 70,1 & 72,3 \\
\hline $\mathbf{5}$ & $\mathbf{1 0 0}$ & 49,2 & 59,5 & 66,0 & 70,7 & 74,4 & 77,6 & 80,4 & 82,9 & 85,2 \\
\hline $\mathbf{2 0 0}$ & 64,9 & 75,9 & 82,5 & 87,3 & 91,2 & 94,4 & 97,3 & 99,8 & 102,2 \\
\hline $\mathbf{5 0 0}$ & 95,5 & 106,9 & 113,7 & 118,6 & 122,6 & 125,9 & 128,8 & 131,4 & 133,8
\end{tabular}


Table 3. The radiotelephone communication ranges of the developed model as a function of the height of the antennas: transmitting and receiving above the sea surface

\begin{tabular}{|c|c|c|c|c|c|c|c|c|c|c|}
\hline & \multicolumn{9}{|c|}{$h_{2}[\mathrm{~m}]$} \\
\hline & & 10,0 & 20,0 & 30,0 & 40,0 & $\mathbf{5 0 , 0}$ & 60,0 & $\mathbf{7 0 , 0}$ & 80,0 & 90,0 \\
\hline & 10 & 26,6 & 32,1 & 36,3 & 39,8 & 43,0 & 45,8 & 48,4 & 50,9 & 53,1 \\
\hline & 30 & 32,1 & 37,6 & 41,8 & 45,4 & 48,5 & 51,3 & 53,9 & 56,4 & 58,6 \\
\hline $\bar{\Xi}$ & 50 & 43,0 & 48,5 & 52,7 & 56,3 & 59,4 & 62,2 & 64,8 & 67,3 & 69,5 \\
\hline$\equiv$ & 100 & 55,3 & 60,8 & 65,0 & 68,6 & 71,7 & 74,5 & 77,1 & 79,6 & 81,8 \\
\hline & 200 & 72,7 & 78,2 & 82,4 & 86,0 & 89,1 & 91,9 & 94,5 & 97,0 & 99,2 \\
\hline & 500 & 107,2 & 112,7 & 116,9 & 120,5 & 123,6 & 126,5 & 129,1 & 131,5 & 133,8 \\
\hline
\end{tabular}

On figure 1 are diagrams of radiophonic and DSC radio coverage ranges for different antenna heights. On figure 2 the graphs of the difference in ranges between the developed model and the empirical model determined from the formula 2 are presented.

Table 4. The DSC communication ranges of the developed model as a function of the height of the antennas: transmitting and receiving above the sea surface

\begin{tabular}{|c|c|c|c|c|c|c|c|c|c|c|}
\hline & \multicolumn{9}{|c|}{$h_{2}[\mathrm{~m}]$} \\
\hline & & 10,0 & 20,0 & $\mathbf{3 0 , 0}$ & 40,0 & $\mathbf{5 0 , 0}$ & 60,0 & $\mathbf{7 0 , 0}$ & 80,0 & 90,0 \\
\hline & 10 & 27,2 & 35,0 & 40,2 & 44,2 & 47,5 & 50,4 & 52,9 & 55,3 & 57,4 \\
\hline & 30 & 35,0 & 44,0 & 49,8 & 54,2 & 57,7 & 60,8 & 63,5 & 66,0 & 68,2 \\
\hline $\bar{\Xi}$ & 50 & 47,5 & 57,7 & 64,1 & 68,8 & 72,6 & 75,8 & 78,5 & 81,0 & 83,4 \\
\hline 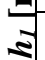 & 100 & 59,5 & 70,4 & 76,9 & 81,7 & 85,5 & 88,7 & 91,5 & 94,1 & 96,4 \\
\hline & 200 & 75,9 & 87,0 & 93,7 & 98,6 & 102,4 & 105,7 & 108,6 & 111,2 & 113,5 \\
\hline & 500 & 106,8 & 118,3 & 125,1 & 130,1 & 134,0 & 137,4 & 140,3 & 142,9 & 145,3 \\
\hline
\end{tabular}

a)

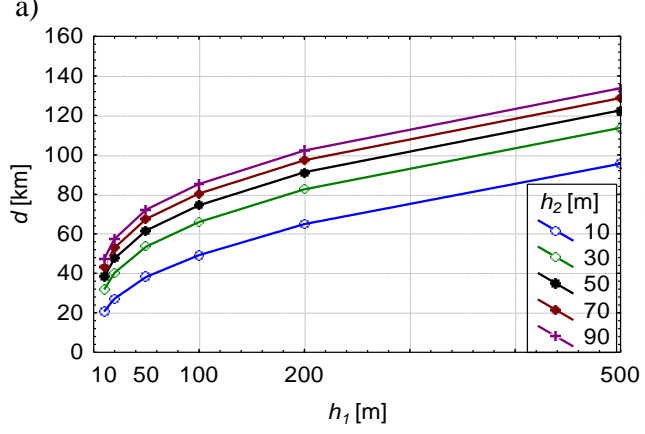

b)

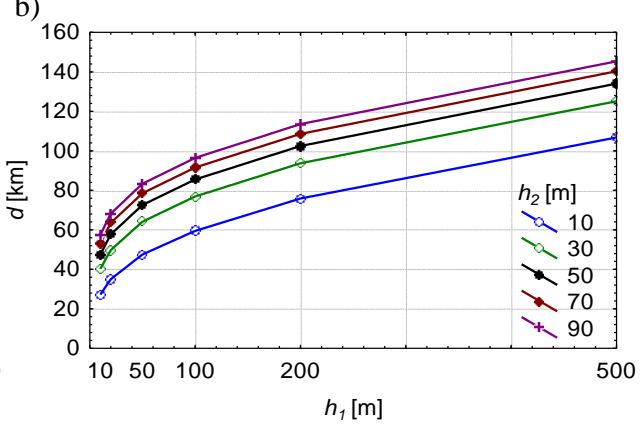

Fig. 1. Graphs of communication ranges $d[\mathrm{~km}]$ of the developed model as a function of the height of the transmitting and receiving antennas above the sea surface: a) radiotelephony, $b$ ) digital selective calling.

a)

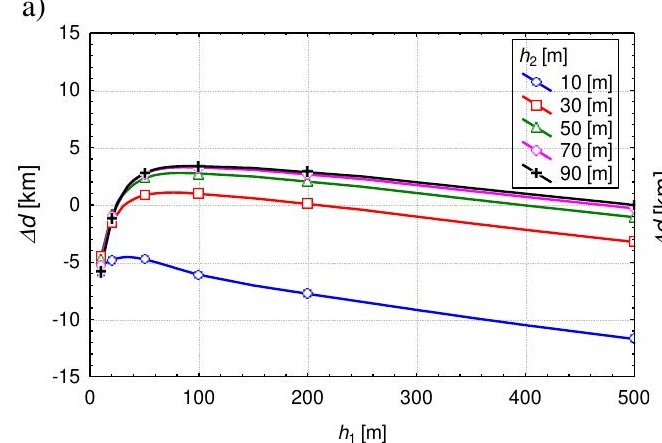

b)

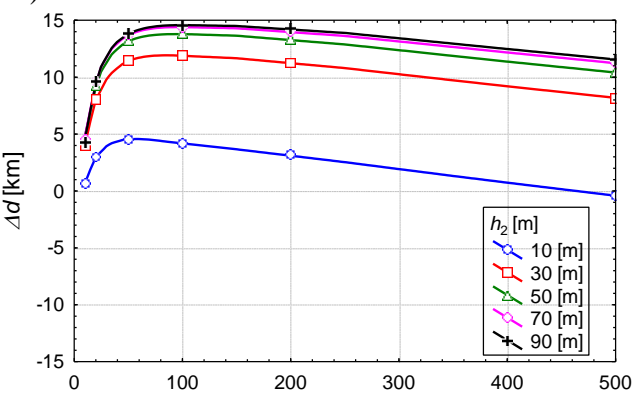


Fig. 2. Graphs of communication ranges difference between of the developed model and empiric model as a function of the height of the transmitting and receiving antennas above the sea surface: a) for radiotelephony, $b$ ) for digital selective calling.

As can be deduced from the graphs, the biggest difference between the developed model and the empirical model occurs when the differences between the positions of the transmit and receive antennas are large.

\section{EXEMPLIFICATION OF THE DEVELOPED RANGE DETERMINATION METHOD}

In order to present the effects of the developed method of determining ranges in the VHF band on figure 3, an example of a situation in which there is an $S_{0}$ shore station and 2 ship stations $S_{1}$ and $S_{2}$ are presented. The height of the shore station antenna was adopted at the height $h=200 \mathrm{~m}$ for ship $S_{l}$ adopted $h=40 \mathrm{~m}$ and ship $S_{2}$ respectively $h=10 \mathrm{~m}$. The continuous line indicates radiofrequency ranges determined according to the empirical formula (2) and the dotted line according to the model developed in the article. The radii of the circles for the shore stations shall be as follows: 66,5; 72,7; 85,95; 88,9 km and for ships $S_{1}$ and $S_{2}: 35,3 \mathrm{i} 39,84$ [km]. As we can see in the drawing, the shore station has no coverage with the ship $S_{2}$ according to the formula (2) developed by the empirical method but has a radio range with the ship $S_{1}$. However, according to the developed model, it is exactly the opposite - the shore station will have communication with the $S_{2}$ ship but will not have a range with the $S_{1}$ ship. For the range between ships $S_{1}$ and $S_{2}$, it can be concluded that there will be no radio coverage between them according to the empirical model but it will be according to the developed model.

According to the presented situation, it was developed and described in articles [Majzner et al., 2014], [Mąka et al., 2017], the matrix of information reception availability for the empirical model (Table 5) and for the model developed in this article (Table 6) shall take the following values:

Table 5. Values matrix of the information reception availability determined for the empirical model

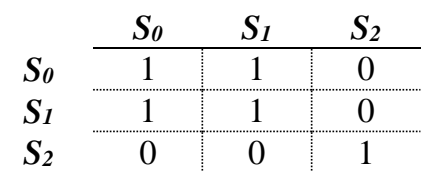

Table 6. Values matrix of the information reception availability determined for the developed model

\begin{tabular}{lc:c:c} 
& $\boldsymbol{S}_{\boldsymbol{0}}$ & $\boldsymbol{S}_{\boldsymbol{1}}$ & $\boldsymbol{S}_{2}$ \\
\cline { 2 - 4 } $\boldsymbol{S}_{\boldsymbol{0}}$ & 1 & 0 & 1 \\
$\boldsymbol{S}_{\boldsymbol{1}}$ & 0 & 1 & 1 \\
$\boldsymbol{S}_{2}$ & 1 & 1 & 1
\end{tabular}




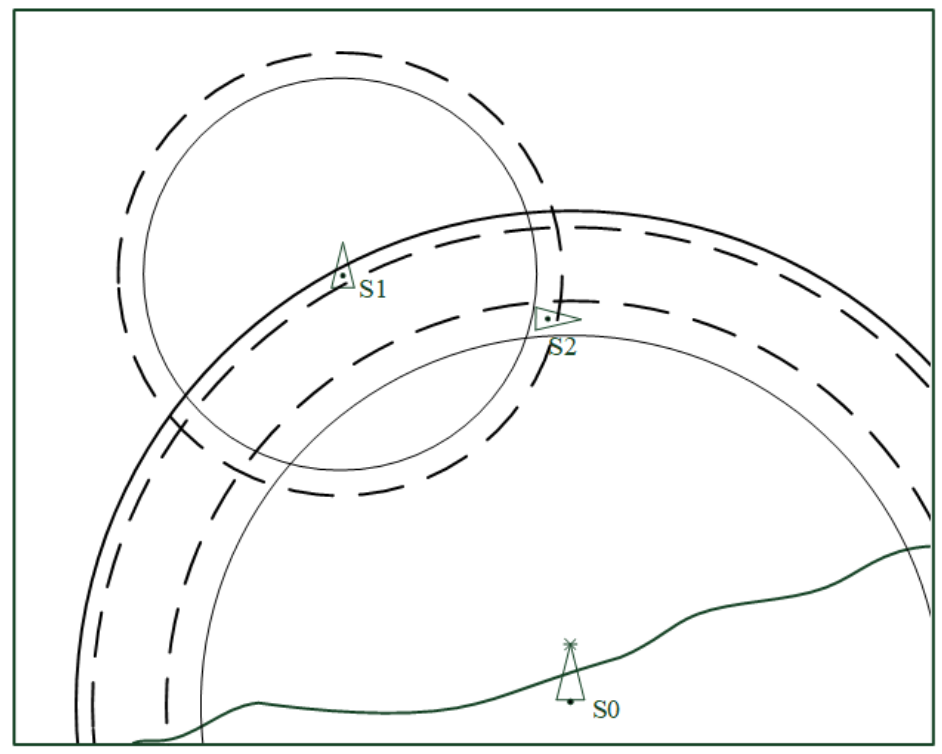

Fig. 3. Deployment and ranges of a radio stations in sea area A1.

Differences between the values of the information availability matrix presented in Tables 5 and 6 , show how differently the decision-making process of the shore and ship station operator may take place depending on the adopted propagation model.

\section{CONCLUSIONS}

This article presents an analytical model of propagation in sea area A1, which is one of the components of the Radiocommunication Events Management System. The authors propose a method of calculation the particular ship and coast radio stations ranges in sea area A1. Based on the article, the following conclusions can be made:

- The developed model due to the inclusion of many parameters of the transmitted signal is more adequate to the reality than the empirical model.

- Differences between the empirical model and the model developed in the article are more significant in the case of large height differences between the antennas of two stations communicating by VHF band.

- The empirical models developed in the article give similar values of ranges in the case when the heights of transmit and receiving antennas do not differ significantly.

- The developed model allows to determine the range also for DSC, which is not allowed by the empirical model.

- The ranges determined by the developed model allow for a more adequate determination of the value of the information availability matrix and, consequently, a more accurate modelling of communication events at sea.

The advantages of the developed method of determining ranges between two stations operating in the VHF band allow for a more accurate analysis of decision-making processes of radio operators, which in turn may lead to a more accurate development of the decision support system for GMDSS radio operators on ships.

\section{REFERENCES}

[1] Czajkowski J.: System GMDSS regulaminy, procedury i obsługa. Skryba, Gdańsk, 2002.

[2] Instytut Łączności, Państwowy Instytut Badawczy, Samodzielna Pracownia Radiokomunikacji Morskiej w Gdańsku: Platforma propagacji. Badania uwarunkowań propagacyjnych w morskim paśmie VHF. Gdańsk, 2006. 
[3] Instytut Łączności, Państwowy Instytut Badawczy, Zakład Systemów Radiowych: Prognozowanie łączności radiowej w zakresach częstotliwości $20-60 \mathrm{GHz}$ w cyfrowych systemach dostępowych i liniach radiowych horyzontowych. Warszawa, 2005.

[4] ITU-A.609: Performance standards for shipborne vhf radio installations capable of voice communication and digital selective calling. Geneva, 2015.

[5] ITU-R P.310-9: Definitions of terms relating to propagation in non-ionized media. Geneva, 08/1994.

[6] ITU-R P.341-6: The concept of transmission loss for radio links. Geneva, 09/2016.

[7] ITU-R P.368-9: Ground-wave propagation curves for frequencies between $10 \mathrm{kHz}$ and $30 \mathrm{MHz}$. Geneva, 02/2007.

[8] ITU-R P.453-13: The radio refractive index: its formula and refractivity data. Geneva, 12/2017.

[9] ITU-R P.525-3: Calculation of free-space attenuation. Geneva, 09/2016.

[10] ITU-R P.526-13: Propagation by diffraction. Geneva, 11/2013.

[11] ITU-R P.527-4: Electrical characteristics of the surface of the Earth. Geneva, 06/2017.

[12] ITU-R P.834-9: Effects of tropospheric refraction on radiowave propagation. Geneva, 12/2017.

[13] ITU-R P.1546-5: Method for point-to-area predictions for terrestrial services in the frequency range 30 MHz to $3000 \mathrm{MHz}$. Geneva, 09/2013.

[14] ITU-R P.1812-4: A path-specific propagation prediction method for point-to-area terrestrial services in the VHF and UHF bands. Geneva, 07/2015.

[15] Katulski R.J.: Projektowanie stacji radiokomunikacyjnej. Przegląd Telekomunikacyjny nr 10/2002. Warszawa, 2002.

[16] Pawłowski W.: Modele propagacyjne dla tras morskich w paśmie 1-3 GHz. VIII Sympozjum Wojskowej Techniki Morskiej, VIII SWTM'01 "Osiągnięcia i perspektywiczne zamierzenia w dziedzinie wojskowej techniki morskiej", Centrum Techniki Morskiej, Gdynia, 2001.

[17] Majzner P., Mąka M.: A simulation model of Radiocommunication Events Management. Scientific Journals of the Maritime University of Szczecin, 37/2014. Szczecin, 2014.

[18] Mąka M., Majzner P.: The radio operator decision support system model. Scientific Journals Maritime University of Szczecin, no. 52/2017. Szczecin, 2017.

[19] Saunders S.R., Aragón-Zavala A.: Antennas \& Propagation for Wireless Communication Systems, 2nd Edition. John Wiley \& Sons, 2007. 